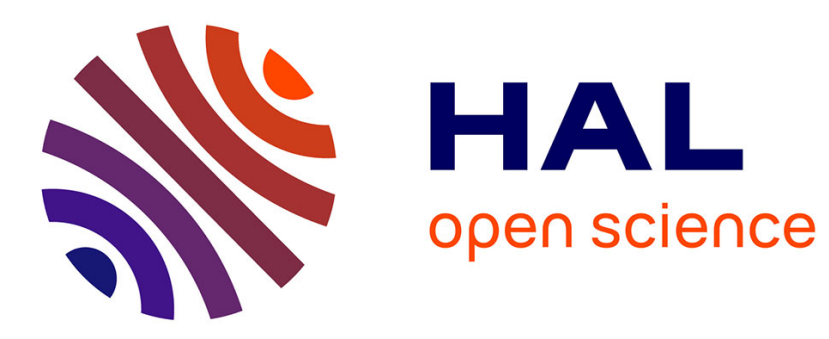

\title{
Water-Ice Exposing Scarps Within the Northern Midlatitude Craters on Mars
}

Harish Harish, S. Vijayan, N. Mangold, Anil Bhardwaj

\section{To cite this version:}

Harish Harish, S. Vijayan, N. Mangold, Anil Bhardwaj. Water-Ice Exposing Scarps Within the Northern Midlatitude Craters on Mars. Geophysical Research Letters, 2020, 47 (14), pp.e2020GL089057. 10.1029/2020GL089057 . hal-02933663

\section{HAL Id: hal-02933663 https://hal.science/hal-02933663}

Submitted on 8 Sep 2020

HAL is a multi-disciplinary open access archive for the deposit and dissemination of scientific research documents, whether they are published or not. The documents may come from teaching and research institutions in France or abroad, or from public or private research centers.
L'archive ouverte pluridisciplinaire HAL, est destinée au dépôt et à la diffusion de documents scientifiques de niveau recherche, publiés ou non, émanant des établissements d'enseignement et de recherche français ou étrangers, des laboratoires publics ou privés. 
1 Water-ice exposing scarps within the northern mid-latitude craters on Mars

2

3

6

2

.

(1)

${ }^{1}$ Planetary Science Division, Physical Research Laboratory, Ahmedabad 380009, India.

${ }^{2}$ Indian Institute of Technology, Gandhinagar 382355, India.

${ }^{3}$ Laboratoire de Planétologie et Géodynamique, Nantes, CNRS UMR6112, Université de Nantes, Université d'Angers, 44322 Nantes, France

\section{Harish $^{1,2 *}$, S. Vijayan ${ }^{1}$, N. Mangold ${ }^{3}$, and Anil Bhardwaj ${ }^{1}$}

(1)

(1)

3

Corresponding author: Harish (harishnandal77@gmail.com)

6

7

\section{Key Points:}

- We report newly identified water-ice deposits exposed by scarps within craters in the northern mid-latitude on Mars

- Ice accumulated within last 25 Myr over the pole- and 95 Myr over equator-facing walls, and exposure time is expected to be $\sim 1 \mathrm{Myr}$

- Temporal spectral evidence reveals conserved water-ice reservoirs on Mars associated with both pole/equator facing wall deposits 


\section{Abstract}

We report new exposures of water-ice along the scarps wall located within craters in the northern mid-latitude region of Mars based on high-resolution imagery and spectral data of Mars Reconnaissance Orbiter. The exposed water-ice deposits are shallower and exhibit 1.5 and $2 \mu \mathrm{m}$ absorption features. These scarps are located on the pole-facing walls and equator-facing wall origin floor deposits, which formed over the latitude dependent mantle deposits. Our observations advance in bracketing the younger ice-deposits through the crater size-frequency distributions of host craters, which formed around $\sim 25$ and $~ 95 \mathrm{Myr}$ and exposed around $\sim 1 \mathrm{Myr}$. This reveals that possible ice transportation, accumulation, and compaction occurred in recent epochs. Our study complements the earlier studies that shallow water-ice is spatially widespread and consistent with subsurface water-ice detection by neutron spectrometer. We interpret the ice remnants likely to preserve in craters pole-facing wall and equator-facing wall-associated floor deposits, which provides evidence to global water-ice resources on Mars.

Plain Language Summary

One-third of the planet Mars is rich in water-ice, which is mostly preserved a few meters below the surface. Identification of new water-ice rich regions is indeed required to understand their spatial spread across Mars. Identification of new water-ice rich locations will have a vital role in identifying future landing/robotic missions on Mars and even for the in-situ resource utilization. Recent high-resolution visible images and infrared wavelength-dependent spectral signature provide more diagnostic evidence for water-ice. In this study, we have reported water-ice exposure within two craters located in the northern hemisphere of Mars. These exposures are found in the crater wall and over the crater floor deposits. We found that on one location, the exposed ice is stable after one week of interval, this gives a direct proof for the stable exposed ice. We determined that these craters are formed a few tens of million years ago, and deposits occurred likely over a few million years. But, the ice deposits within a crater is exposed within a million year ago. We append our new locations to the existing list of identified water-ice deposits and ensure the widespread of water-ice few meters below the surface of Mars. 


\section{Introduction}

Water-ice on Mars is a vital source for identifying and determining the aqueous history of the planet. The occurrence of shallow ground water-ice can be used to infer the snow accumulation processes and related climatic conditions that prevailed on Mars. Also, these shallow water-ice rich locations can be prime target sites for future missions to Mars (Head et al., 2003; Bandfield, 2007; Schulze-Makuch et al., 2016; Dundas et al., 2018; Piqueux et al., 2019) specifically the northern mid-latitude regions because of their low elevation and smooth terrain (Piqueux et al., 2019). Precipitation, accumulation, and compaction of snow would have caused formation of massive (few meters to hundreds of meters thick) water-ice layers during the high obliquity $\left(>30^{\circ}\right.$ ) periods of Mars (Head et al., 2003; Mangold et al., 2004; Bandfield, 2007; Dundas et al., 2018; Piqueux et al., 2019). These compacted shallow water-ice layers are located few meters to tens of meters below the surface and suggested to cover one-third of the planet Mars (Mangold et al, 2004; Bandfield, 2007; Dundas et al., 2018).

Shallow ground water-ice on Mars can be found in the form of pore-filling or massive, nearly pure water-ice (Mangold et al, 2004; Bandfield, 2007; Mellon et al., 2009; Cull et al., 2010; Dundas et al., 2018). Dundas et al. (2018) reported exposures of pure water-ice deposits in cliff scarps at eight locations, predominant over the south-eastern side of the Hellas basin, and only one location in the northern lowlands within the Milankovič crater. Piqueux et al. (2019) reported widespread shallow water-ice in the high and mid-latitude up to $35^{\circ} \mathrm{N} / 45^{\circ} \mathrm{S}$ of Mars based on trends of seasonal surface temperature. However, direct spectral observations of spatially distributed shallow ground water-ice in the northern mid-latitude are limited. Along with that, earlier studies (Mellon \& Jakosky, 1995; Mellon et al., 1997, 2004; Jakosky et al., 2005; Bandfield, 2007; Chamberlain \& Boynton, 2007; Schorghofer \& Forget, 2012) suggested instability of surface water-ice in mid-latitude, however, stable ground water-ice favored below a dust cover (Head et al., 2003; Mangold et al, 2004; Dundas et al., 2018). Based on the slope orientation, Aharonson and Schorghofer (2006) and Dundas et al. (2018) suggested that waterice can be comparatively more preserved over the pole-facing walls of the craters on Mars. Independent of the pole-facing scenario, Vincendon et al. (2010) suggested that shallow ground water-ice in the mid-latitude region of Mars can survive throughout the whole year. However, the period of accumulation of water-ice in the mid-latitude regions and its preservation on equatorfacing crater walls is not known. 
The craters in the mid-latitude regions record the history of snow transport across regions, and those craters could be the potential reservoirs to refine our understanding of the recent climatic conditions. In this context, we have identified two unnamed craters (UC1 and UC2) in the northern lowlands of Mars (Fig. 1, S1) with a clear signature of water-ice exposures. The identification of new craters with preserved exposure of water-ice deposits is indeed important to support the widespread global interpretation of shallow water-ice and its use as a resource in the perspective of manned exploration. The detection of more ice-rich locations on Mars at different spatial extent will help in deciding future explorations, landing site, and in-situ resource utilization.
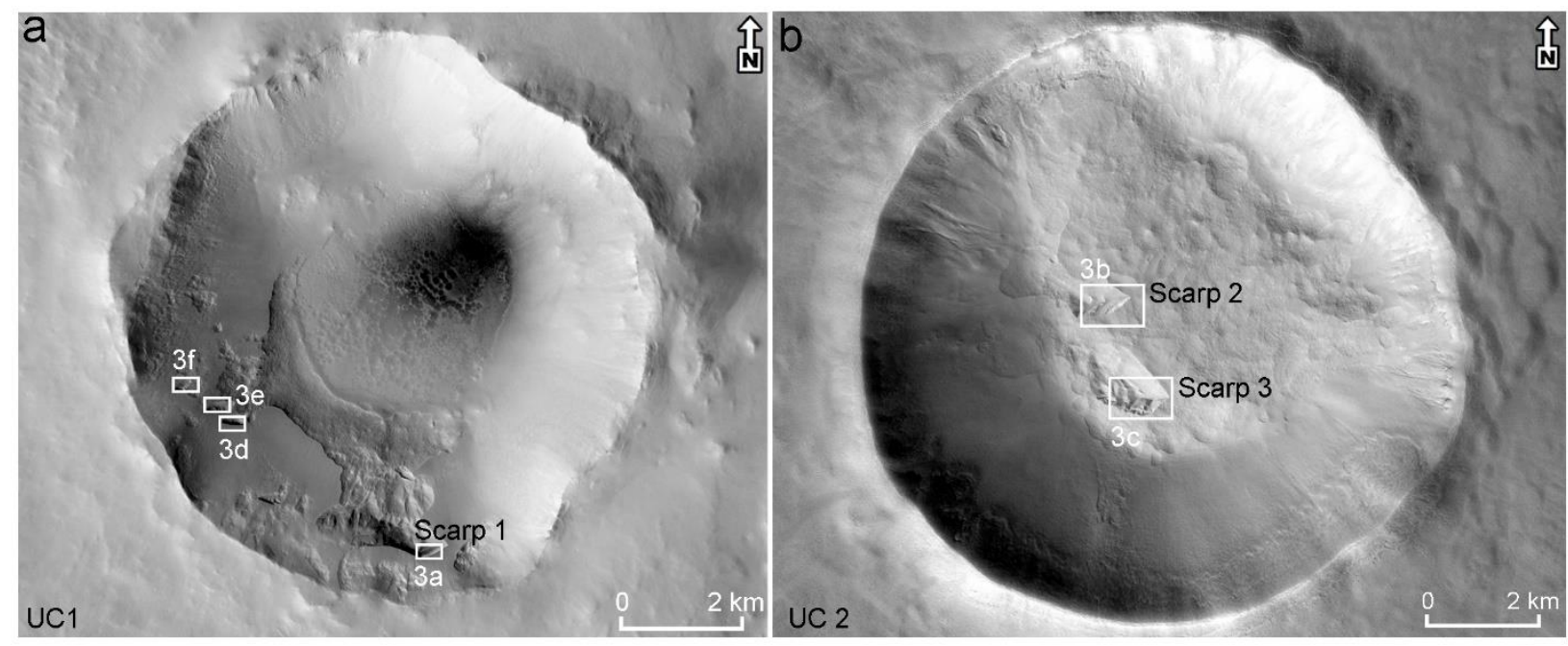

Fig. 1. Two unnamed craters (UC1 and UC2) located in the northern lowlands of Mars. a) UC1 crater centered at $55.3^{\circ} \mathrm{N}$ and $106.4^{\circ} \mathrm{W}$ with scarps on pole-facing wall. b) UC2 crater is centered at $57.0^{\circ} \mathrm{N}$ and $95.7^{\circ} \mathrm{E}$ with scarps on its floor.

\section{New observation and Results}

The two unnamed craters identified in this study are shown in Fig. 1. Fig. S1 displays the locations of these two craters along with the other locations of shallow ground water-ice deposits reported by Dundas et al. (2018). Both the craters are $\sim 11 \mathrm{~km}$ in diameter, where UC1 is $\sim 1.1 \mathrm{~km}$ deep and UC2 is $~ 800 \mathrm{~m}$ deep, with preserved layered ejecta. The crater UC1 is located to the north of Alba mons (Fig. 1a, S1), whereas the crater UC2 is located to the west of Utopia Planitia (Fig. 1b, S1). Spatially, these craters are located $\sim 5100 \mathrm{~km}$ apart, but located almost in the same latitude and with exposed scarps (Fig. 1). Scarps on Mars are known as erosional features, which are interpreted to retreating actively due to the ice sublimation (Dundas et al., 2018). They 
generally have steep walls (slope $>40^{\circ}$ ) and reveals the vertical structure of the shallow ground (Dundas et al., 2018). Within the UC1 southern wall, there are four major scarps, few small scarps, and one large scarp with collapsed nature (Fig. 1a). Crater UC2 has two scarps, both are located on top of the wall origin floor deposits (Fig. 1b).

\subsection{Spectral analysis}

The CRISM color composite maps are generated by using the summary product BD_1500 derived similarly to Viviano-Beck et al., (2014). These derived false-color composite images for crater UC1 (Fig. S2) and crater UC2 (Fig. S3) are used to decipher the water-ice regions. From the BD_1500 highlighted water-ice regions (Fig. S2b,d, S3b), we extracted the water-ice spectra from 12 regions of interest (Table S1,S2), which falls within the scarps (colored boxes in Fig. S4, S5). Fig. 2a,b shows ratioed CRISM spectra from scarp1, located on the pole-facing wall of crater UC1, using temporal images (Table S1). The spectra extracted from the scarp1 have absorptions near $1.5 \mu \mathrm{m}$ and $2 \mu \mathrm{m}$ wavelength, which indicates water-ice (Viviano et al., 2015; Dundas et al., 2018). Apart from the scarp1, no significant signature of water-ice spectra is seen within the crater UC1 (Fig. S2). The possible reasons for the absence of ice signatures could be: poor signal to noise ratio, location of their exposure, high dust cover and/or sublimation of ice partially or completely masking the water-ice and old scarps with longer exposure time (Cull et al., 2010; Dundas et al., 2018).

Fig. 2c,d shows CRISM spectra for scarp2 and 3, which are located on the floor of the crater UC2, and are characterized by $1.5 \mu \mathrm{m}$ and $2 \mu \mathrm{m}$ absorption, which confirms the water-ice deposits. In scarp2, the observed water-ice spectral signatures are spatially spread few tens of meters along the wall (Fig. S5) suggesting their wide exposure within the scarp. In scarp3, the spectral signature of water-ice are observed to spread a few tens of meters vertically or across the scarp wall. Though the scarps 2 and 3 are formed over the floor deposits (Fig. 1b), however, these floor deposits originated from the equator-facing wall of crater UC2 (see section 2.2). Our study 

for crater floor preserving the ice deposits.

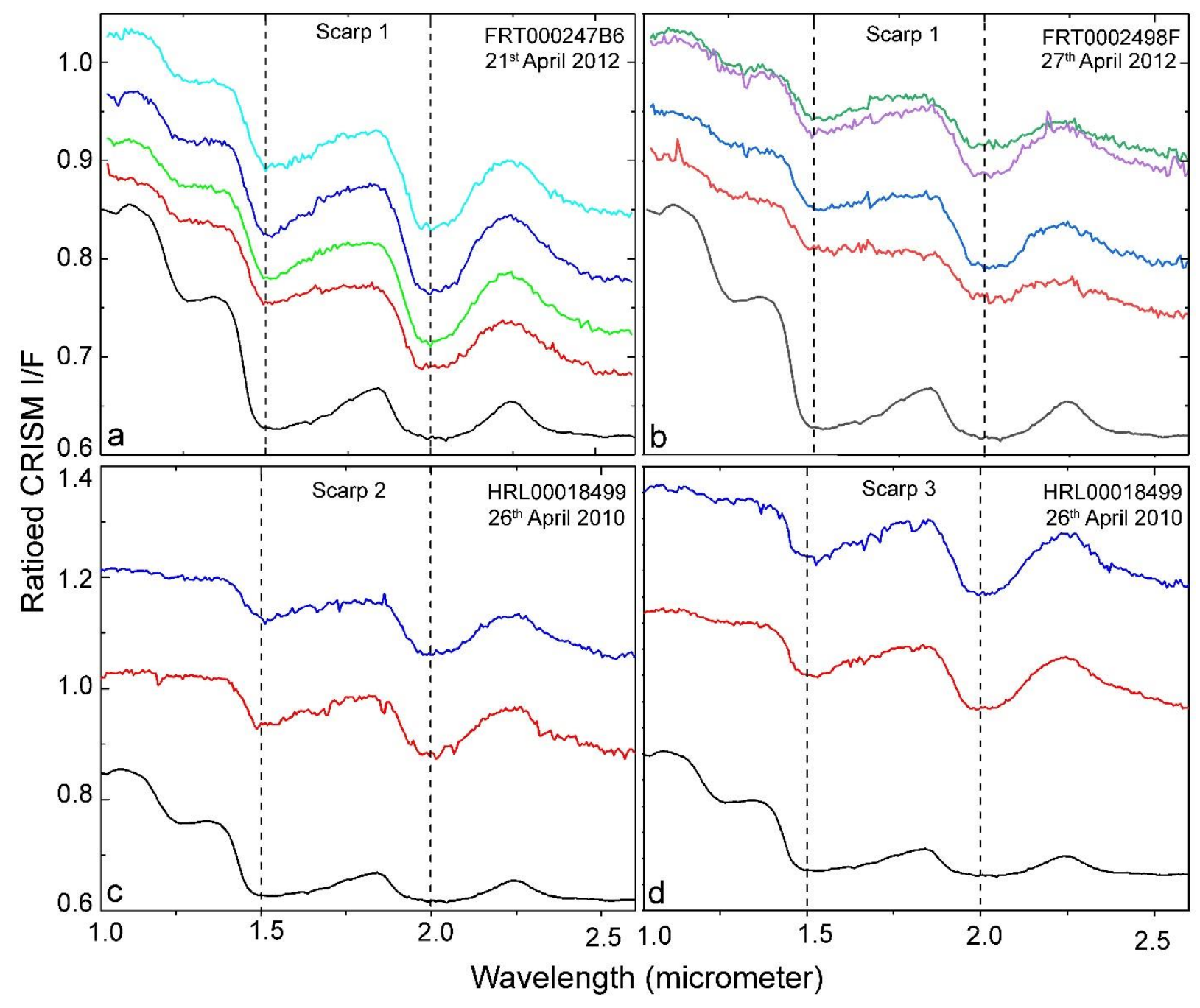

Fig. 2. CRISM spectrum within the scarps. a) Spectrum for water-ice extracted from the Scarpl b) Spectrum of water-ice extracted from the same Scarpl within one-week temporal CRISM image for the same location. c) Spectrum of water-ice from Scarp2, d) Spectrum of water-ice extracted from Scarp3 (for spectrum locations refer Fig. S4,S5). Black line is the reference spectrum from MRO CRISM spectral librarv (Viviano-beck et al.. 2015) absorptions depth. A relatively shallower absorption is seen in the spectrum after a week (Fig. 2b). These images were acquired in MY 31 during the last phase of northern spring similar to Dundas et al. (2018). It may be noted that though the spectra shown in Fig. 2a,b are taken from the scarp1, however, they are not exactly from the same pixels. The factors like difference in pixel, one-week 
temporal image, and viewing geometry may be the possible reasons that cause variations in the reflectance spectra. Overall, the small temporal variations of water-ice spectrums provide vital evidence that the exposed water-ice can probably last for a certain duration on Mars.

\subsection{HiRISE observations}

Fig. 3 shows the HiRISE false-color RGB images (Table S3) for water-ice scarps present within both the craters. There are three major scarps (Fig. 3a-c) in which we observed spectral evidence for water-ice (Fig. 2). In crater UC1, the scarps are formed over the pole-facing wall (Fig. 1a) and scarp1 is located nearly $1 \mathrm{~km}$ downward from the southern rim. Fig. S6 shows the vertical structure of the pole-facing crater wall, over which the scarp 1 is located, whose steepsided wall has a slope of $\sim 45^{\circ}$ with exposed ice. Crater topographic profile across the scarp1 reveals its steep slope $\left(\sim 45^{\circ}\right)$ at the location where the ice is exposed, which is much higher than the average slope of the crater wall $\left(\sim 15^{\circ}\right)$ (Fig. S7a). Within the scarp1 (Fig. 3a), we observed three layers: an uppermost bluish-white layer similar to Dundas et al. (2018), a middle dark-toned layer appears as dust-covered with non-ice deposits, and a lowermost layer with bluish-white color again. From the uppermost layer, we obtained the water-ice spectral signature (Fig. 2a,b). We determined the elevation of scarp1 is $\sim 2 \mathrm{~km}$ below the Martian geoid. We estimate the uppermost exposed water-ice deposit thickness to be at least $\sim 20 \mathrm{~m}$, whereas the exposed scarp total vertical length is $\sim 150 \mathrm{~m}$ after correcting for the regional slope. Due to the absence of the CRISM waterice spectrum, it is difficult to identify the lowermost bluish layer in HiRISE false color as a waterice deposit (Fig. 3a). The viewing geometry and high slope make it difficult to get any spectrum from this bottom-most layer. Hence we are left out to make photo-geological interpretation with HiRISE images. Keszthelyi et al. (2008) reported that the dust deposits may also result in the bluish color in the HiRISE imagery. The western part of scarp1 and the adjoining floors are bluish, which is due to dust mantling (Keszthelyi et al., 2008). However, the third bottom-most layer is more towards bluish-white tone, whereas the immediate floor lacks such bluish-white color. This interpretation resulted in hypothesizing that this layer could be one ice layer. Thus, the scarp1 over the pole-facing wall exposed the possible layered ice deposits as anticipated in earlier studies (Dundas et al., 2018; Piqueux et al., 2019). This suggests that the current to past climatic 
conditions could have formed internal layering (Bramson et al., 2017; Schorghofer and Forget, 2012) and these may be exposed on the scarp1 walls.

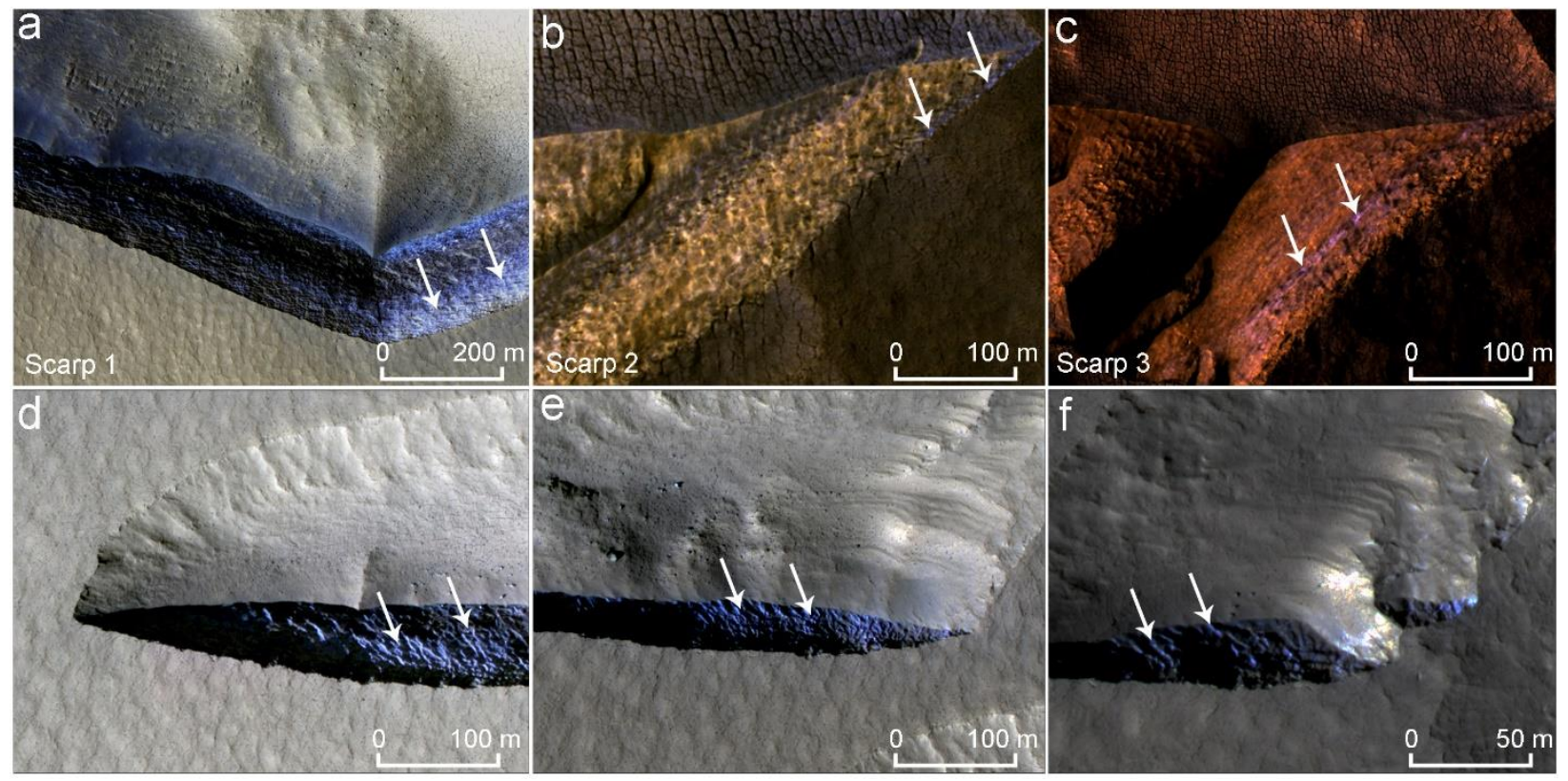

Fig. 3. False colored HiRISE images with bluish-white contrast represent the water-ice rich regions (a-c) and spectrum shown in Fig. 2 were extracted from these scarps. (d-f) shows bluish color, however, no prominent water-ice spectra observed here. North is up and sun-light is from the left in all figures (a-f). (HiRISE images a:ESP_026959_2355, b-c:ESP_018420_2375, d-f:ESP_062853_2355)

Fig. 3b shows the false and enhanced HiRISE color image of scarp2 within the crater UC2 with very little bluish-white contrast in the upper part of the scarp. The strong spectral signature from this location (Fig. 2c) coincides with the HiRISE observations and demonstrates this bluishwhite layer as potential water-ice. Scarp3 (Fig. 3c) within the UC2 crater also shows a thin bluishwhite color and has a strong water-ice spectral signature (Fig. 2d). The coordinated HiRISE interpretation in scarp2 and 3 are highly supported by CRISM spectral signatures (Fig. 2c,d) and reveals that such a small quantity of ice exposures, if not covered by dust, is capable of being detected by CRISM.

Apart from the spectrally distinguishable water-ice signature within scarps, we observed few scarps with bluish-white tone in UC1 from HiRISE images (Fig. 3d-f). However, these scarps (Fig. 3d-f) do not have any distinguishable spectral signatures from CRISM. These scarps have a bluish-white tone that is notably different from the bluish color due to the dust cover (Keszthelyi et al., 2008). We propose that these scarps (Fig. 3d-f) host possible water-ice exposures based on 
their close vicinity to water-ice rich scarp1. Moreover, all the scarps are located over the bumpy textured latitude dependent mantled (LDM) unit (Kreslavsky and Head, 2002; Head et al., 2003; Levy et al., 2011). Fig. S8 shows the preserved LDM unit over the southern wall, whereas the rest of the southern wall is eroded. Moreover, all the exposed scarps share boundaries with the LDM unit (Fig. S8). Therefore, we likely interpret that all the scarps shown in Fig. 3d-f may contain water-ice signatures. However, the role of ice sublimed over a long period (Dundas and Byrne, 2010) is not contested, and these exposures may partially be covered by dust.

In crater UC2, both the scarps are located within the floor deposits (Fig. 1b), The two scarps within UC2 are spatially separated by $\sim 2 \mathrm{~km}$ from each other and have an elevation difference of $\sim 100 \mathrm{~m}$. Scarp2 is located on the mid of the floor deposit, whereas scarp3 is located at the toe of the deposits (Fig. S7b). Topographic profile across the crater UC2 and through the scarps 2 and 3 (Fig. S7b) shows a higher slope over the pole-facing wall $\left(\sim 13^{\circ}\right)$ than the equatorfacing wall $\left(\sim 9^{\circ}\right)$. This we interpret as that the material from the equator-facing wall deposited over the floor (Berman et al., 2009). The water-ice deposits which currently rest on the crater floor are originated from the equator-facing wall with due erosion of wall material. Based on the UC2 crater observation, we infer that not only the pole-facing wall (Fig. S7a) host the ice deposits, but the equator-facing wall origin floor deposits (Fig. S7 b) also host buried ice. Our study provides evidence that both the pole- and equator-facing walls of craters are likely for snow accumulation and preservation of water-ice.

Other scarps within the UC1 crater (Fig. S9), that are located near the smooth LDM unit (Kreslavsky and Head, 2002; Head et al., 2003) lack HiRISE bluish-white tone and water-ice signature. The possible reason could be that these scarps are older exposures, where the ice could have sublimed over the time (Dundas and Byrne, 2010; Vincedon et al., 2010) and currently appear as dry scarp. These dry scarps are different from the water-ice-rich scarps as they lack a bluish-white tone in the HiRISE images (e.g. Dundas et al., 2018). Such scarps with complete lack of water-ice (Fig. S9) could be used to infer that whether the ice reported within the scarp1 is exposed or seasonal deposits (Schorghofer and Edgett, 2006). The water-ice-rich scarp1 (Fig. 1a) and the dry scarps (Fig. S9) are located $\sim 1 \mathrm{~km}$ apart. In addition, these dry scarps (Fig. S9) are located within the same elevation range of water-ice-rich scarp1. If seasonally driven ice deposits are mantled over this latitude and within scarp1, then such deposits are anticipated in these nearby 
scarps (Fig. S9). However, no such spectral signature or geomorphic evidence for water-ice is found in these dry scarps. This suggests that the ice present within the scarp1 is exposed rather than seasonal driven. To support this, we also found that the average temperature value at the scarp1 (minimum $228 \mathrm{~K}$ ) is above the likely frost point of water (Dundas et al., 2018). We interpret that initially ice/snow would have accumulated by the atmospheric precipitation and later vapour diffusion process (Fisher, 2005) may acted over this region Along with the previous evidence of subsurface water-ice exposed by scarps (Dundas et al., 2018), our spectral and HiRISE observations indicate that the ice exposed by the scarps is subsurface ice rather than persistent seasonal frost (Dundas et al., 2018).

\subsection{Chronological relationship}

Crater ejecta is used to estimate the upper ages for the ice exposures. Crater size-frequency distribution for crater UC1 (Fig. 4, S10) tends n=101, whose diameter ranges from $\sim 60 \mathrm{~m}$ to $\sim 300$ $\mathrm{m}$. The derived best fit model age for crater UC1 formation is $\sim 25 \mathrm{Myr}$ by fitting 81 craters with diameter $>85 \mathrm{~m}$ (Fig. 4). This age represents the crater formation age, whereas all the scarps formed over the wall will be younger than the smooth LDM unit. The tentative age of the smooth unit is estimated to infer the possible time frame after which the scarps have formed. The smooth unit surrounding the scarp1 (Fig. S8) lacks superposed craters even at HiRISE resolution. In this regard, as a possible alternative, we utilized tens of meter-scale bumpy texture (Head et al., 2003; Levy et al., 2011) of the smooth unit (Fig. S8), which formed due to the ice mantling. Such texture could hide or have deformed the small craters $<20 \mathrm{~m}$ in diameter. Thus, considering this limit, we have determined that the crater density would be given by the presence of 1 crater of typical size $>20 \mathrm{~m}$ and plotted the same in the differential crater distribution plot of Hartmann (2005). The plot shows (Fig. S11) that it is statistically likely that the tentative age of the smooth unit is $\sim 1$ Myr or younger (Viola, 2020) and the scarp1 could have exposed the water-ice in last 1 Myr.

For crater UC2, our crater count statistics over the ejecta tend $n=31$ and the diameter of the superposed crater ranges from $\sim 30 \mathrm{~m}$ to $\sim 515 \mathrm{~m}$. We obtained the best fit model age as $\sim 95 \mathrm{Myr}$, by fitting 11 craters whose diameter is $>\sim 200 \mathrm{~m}$ (Fig. 4). This crater floor is hummocky and lacks superposed craters. Thus, we limited our chronological interpretation only from crater ejecta. We infer that the crater UC2 either represents an older ice deposit (post crater formation) contained within the wall deposits that are exposed more recently or it represents a younger material 
accumulated more recently during the high obliquity of Mars (Laskar et al., 2004; Viola et al., 2015; Dundas et al., 2018). Irrespective of any scenario, UC2 reveals that within the last $95 \mathrm{Myr}$ the obliquity and climatic conditions favored equator-facing wall deposits within the mid-latitude craters on Mars (Dickson et al., 2012). Crater UC1 provides evidence for ice precipitation, and accumulation over the pole-facing wall occurred within the last 25 Myr (e.g. Viola et al., 2015; Dundas et al., 2018). Regardless of the crater formation age, the ice deposits exposed in these two craters reveal that these scarps are formed recently compared to impact craters age, due to which they are capable of retaining the exposed water-ice till present.

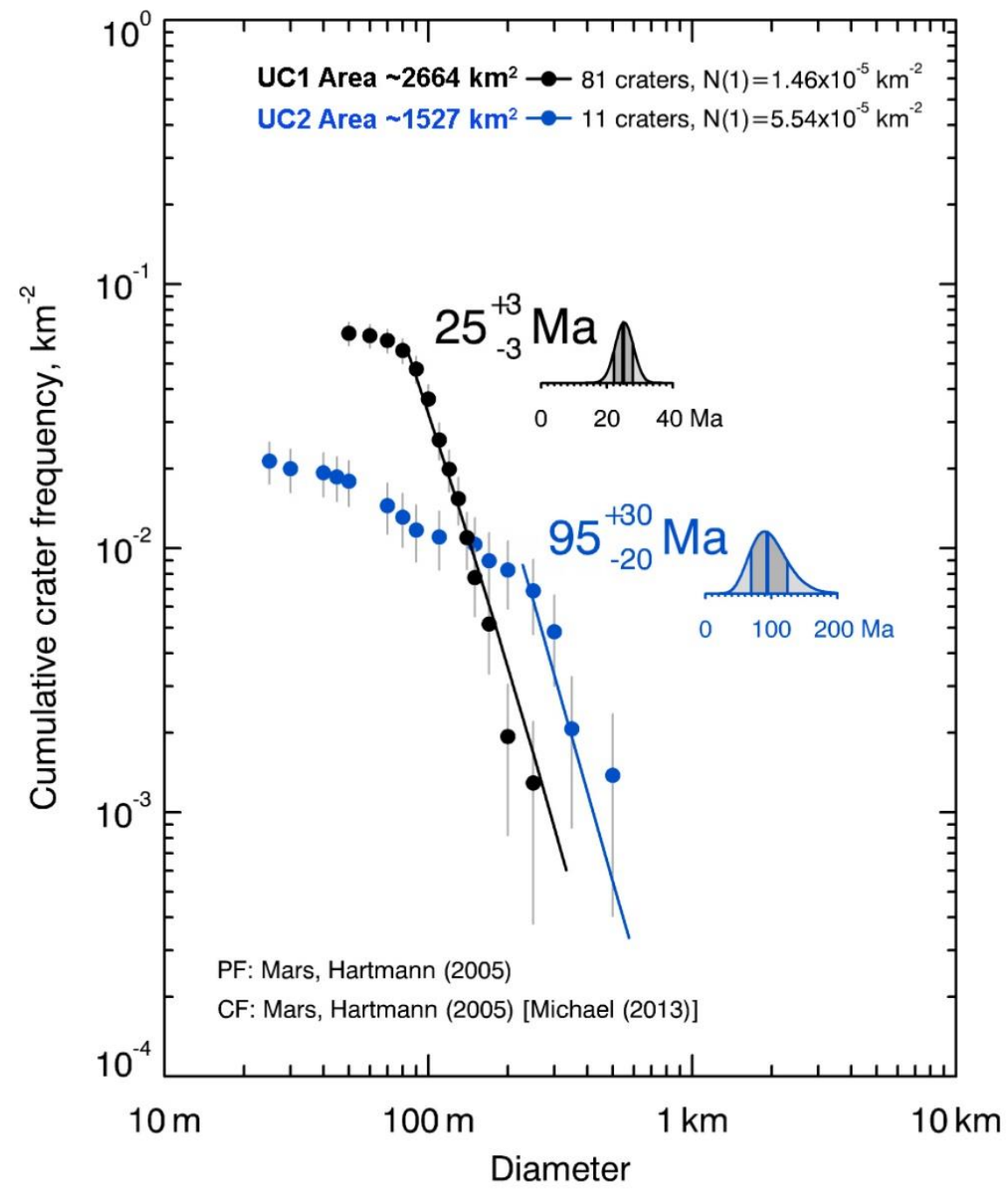

Fig. 4. Crater size-frequency distribution ages for the UC1 and UC2 craters Cumulative fit using Poisson analysis derived age tend to $25 \mathrm{Ma}$ and $95 \mathrm{Ma}$. 
Water-ice deposits have been identified in the northern plains of Mars using Neutron spectroscopy (Feldman et al., 2002; Mangold et al., 2004) and seasonal surface temperature variations (Bandfield, 2007; Piqueux et al., 2019), suggesting they will be shallow ( $<1-2 \mathrm{~m}$ depth). Fig. S12 reveals the correlation between the locations of water-ice in the mid- to highlatitudes (Mangold et al, 2004), and our two reported craters match unprecedentedly. Hence, our results are consistent with orbital detection of hydrogen at shallow depth (Feldman et al., 2002; Mangold et al., 2004; Bandfield, 2007; Dundas et al., 2018; Piqueux et al., 2019), but we add to this story that both pole- and equator-facing (Aharonson and Schorghofer, 2006; Sinha and Vijayan, 2017) deposits within the craters could host significantly preserved water-ice. The waterice/glacial origin deposits are predominantly observed only in the pole-facing walls within craters (Aharonson and Schorghofer, 2006; Sinha and Vijayan, 2017; Dundas et al., 2018). In contrast, deposits over the equator-facing walls remains an enigma. The equator-facing walls are more prevalent to the gully and glacial origin landforms with preserved ice deposits between $\sim 45^{\circ}$ and $60^{\circ}$ (Berman et al., 2009; Dickson et al., 2012) during the Amazonian period. In UC2, we anticipate that ice possibly accumulated all over the crater wall and this is evident from the mantling of LDM unit (Fig. 1b). Dickson et al. (2012) suggested that net accumulation of ice occurs on all surfaces within craters poleward of $\sim 45^{\circ}$. The floor of UC2 crater hosts a thick deposit $(>100 \mathrm{~m})$ with a continuous association with the North-North East wall. Using the topographic profile (Fig. S7b), we interpreted that this deposit has been eroded from the equator-facing wall and settled over the floor. Thus, a significant contribution of floor material is obtained from the equator-facing wall deposits (Fig. S7b), where it remains preserved until younger epochs. Such a scenario can be explained by the obliquity trends on Mars that change over time (Laskar et al, 2004; Viola et al., 2015).

In this scenario, the adjoining question that arises is whether all the wall deposits will host water-ice? It is anticipated that these two craters are spatially apart by $5100 \mathrm{~km}$ and similar waterice deposits are reported in previous studies which suggested a global mid- to high- latitude distribution of ice on Mars (Mangold et al., 2004; Bandfield, 2007; Dundas et al., 2018; Piqueux et al., 2019).

Scarps within the crater floor and walls reveal the preserved vertical structure of young ice deposits at mid-latitudes. The presence of scarps with no water-ice (Fig. S9) which are in the close 
vicinity to ice-rich scarp1 (Fig. 3a, S8), reveals that the scarps formation is a complex process. The one-week interval spectral signatures provide evidence that the current temperature and pressure conditions on Mars are not subliming the ice or that the sublimation rate is slow (Jakosky et al., 2005; Chamberlain \& Boynton, 2007; Dundas and Byrne, 2010; Schorghofer \& Forget, 2012; Dundas et al., 2018). Though the temporal difference is short, it provides spectral evidence that the ice on Mars can be exposed on the surface for quite a long time (Vincedon et al., 2010; Dundas et al., 2014). The possible layered ice deposits within the scarp1 (Fig. 3a) over the polefacing wall, and UC2 crater equator-facing wall origin floor-ice deposits likely indicate multiple cycles of deposition of ice-rich mantles or linked to obliquity conditions (Berman et al., 2009; Dickson et al., 2012).

\section{Conclusions}

We demonstrated the sustainability of shallow ground water-ice deposits on Mars using spectral observations of CRISM and morphological observations of HiRISE. We have shown strong evidence that the pole-facing wall deposits and equator-facing wall-associated floor deposits within the craters at mid-latitudes contain buried shallow water-ice. Our study provides evidence for the water-ice deposits preserved and exposed on the crater floor which originated from the equator-facing wall. The exposure of water-ice deposits on the floor specifically implies that the mid-latitude craters with pole/equator facing deposits can be potential reservoirs for waterice, which depends on the period and obliquity of Mars. Our chronological analysis reveals evidence for snow precipitation, accumulation and compaction of water-ice within the last $25 \mathrm{Myr}$ and expose by scarps within the last $1 \mathrm{Myr}$ in $\mathrm{UC} 1$ crater. Thus, we interpret that the pole-facing walls and equator-facing wall origin deposits within northern mid-latitude craters are more likely to preserve shallow ground water-ice, which can be of prime interest for future robotic/human missions to Mars, and vital for understanding the climatic conditions that prevailed at different epochs.

\section{Acknowledgments}

The work at the Physical Research Laboratory was supported by the Department of Space, India. NM acknowledges the support from the Centre National d'Etudes Spatiales (CNES), France. We thank the MRO mission team for acquiring the CTX, HiRISE and CRISM images. All the 
datasets used in this manuscript can be accessed from the website (http://ode.rsl.wustl.edu/mars/). We thank the NASA AMES Stereo Pipeline and MarsSI for developing CTX-DEM.

\section{References}

Aharonson, O., \& Schorghofer, N. (2006), Subsurface ice on Mars with rough topography. Journal of Geophysical Research, 111, E11007. https://doi.org/10.1029/2005JE002636

Bandfield, J. L. (2007), High-resolution subsurface water-ice distributions on Mars. Nature, 447(7140), 64-67. https://doi.org/10.1038/nature05781

Bramson, A. M., Byrne, S., \& Bapst, J. (2017), Preservation of mid-latitude ice sheets on Mars. Journal of Geophysical Research: Planets, 122, 2250-2266.

https://doi.org/10.1002/2017JE005357

Berman, D.C., Crown, D.A., and Bleamaster III, L.F. (2009), Degradation of mid-latitude craters on Mars. Icarus, 200, 77-95.

Chamberlain, M. A., \& Boynton, W. V. (2007), Response of Martian ground ice to orbit-induced climate change. Journal of Geophysical Research, 112, E06009.

https://doi.org/10.1029/2006JE002801

Cull, S., Arvidson, R. E., Mellon, M. T, Skemer, P., Shaw, A., Morris, R. V. (2010), Compositions of subsurface ices at the Mars Phoenix landing site. Geophys. Res. Lett. 37, L24203. DOI:10.1029/2010GL045372

Dickson, J.L., Head, J.W., and Fassett, C.I. (2012), Patterns of accumulation and flow of ice in the mid-latitudes of Mars during the Amazonian. Icarus, 219, 723-732.

Dundas, C. M., and Byrne, S. (2010), Modeling sublimation of ice exposed by new impacts in the martian mid-latitudes. Icarus, 206, 716-728.

Dundas, C. M., Byrne, S., McEwen, A. S., Mellon, M. T., Kennedy, M. R., Daubar, I. J., \& Saper, L. (2014), HiRISE observations of new impact craters exposing Martian ground ice. Journal of Geophysical Research: Planets, 119, 109-127. https://doi.org/10.1002/2013JE004482 
Dundas, C.M., Bramson, A.M., Ojha, L., Wray, J.J., Mellon, M.T., Byrne, S., McEwen, A.S., Putzig, N.E., Viola, D., Sutton, S., Clark, E., \& Holt, J. W. (2018), Exposed subsurface ice sheets in the Martian mid-latitudes. Science, 359, 199-201. DOI:10.1126/science.aao1619 Feldman, W. C., et al. (2002), Global distribution of neutrons from Mars: Results from Mars Odyssey, Science, 297(5578), 75- 78, DOI:10.1126/science.1073541.

Hartmann, W.K. (2005), Martian cratering 8: Isochron refinement and chronology of Mars. Icarus, 174, 294-320.

Head, J. W., J. F. Mustard, M. A. Kreslavsky, R. E. Milliken, and D. R. Marchant (2003), Recent ice ages on Mars, Nature, 426(6968), 797-802.

Jakosky, B. M., Mellon, M. T., Varnes, E. S., Feldman, W. C., Boynton, W. V., \& Haberle, R. M. (2005), Mars low-latitude neutron distribution: Possible remnant near-surface water-ice and a mechanism for its recent emplacement. Icarus, 175(1), 58-67. https://doi.org/10.1016/j.icarus.2004.1011.1014

Keszthelyi, L., Jaeger, W., McEwen, A., Tornabene, L., Beyer, R.A., Dundas, C., and Milazzo., M. (2008), High-Resolution Imaging Science Experiment (HiRISE) images of volcanic terrains from the first 6 months of the Mars Reconnaissance Orbiter Primary Science Phase. Journal of Geophysical Research, 113, E04005, DOI:10.1029/2007JE002968

Kreslavsky, M.A. and Head, J.W. (2002), Mars: Nature and evolution of young latitude-dependent water-ice-rich mantle. Geophysical Research Letters, 29, 15, 1719. 10.1029/2002GL015392

Laskar, J., Correia, A.C., Gastineau, M., Joutel, F., Levrard, B., Robutel, P. (2004), Long term evolution and chaotic diffusion of the insolation quantities of Mars. Icarus, 170, 343-364.

Levy, J.S., Head, J.W., Marchant, D.R. (2011), Gullies, polygons, and mantles in Martian permafrost environments: cold desert landforms and sedimentary processes during recent Martian geological history. Geological Society, London, Special Publications, 354, 167-182, 1. https://doi.org/10.1144/SP354.10

Mangold, N., Maurice, S., Feldman, W.C., Costard, F., Forget, F. (2004), Spatial relationships between patterned ground and ground ice detected by the Neutron Spectrometer on Mars. Journal of Geophysical Research, 109, E08001, DOI:10.1029/2004JE002235 
Mellon, M. T., \& Jakosky, B. (1995), The distribution and behavior of Martian ground ice during past and present epochs. Journal of Geophysical Research, 100, 11,781-711,799.

Mellon, M. T., Jakosky, B. M., \& Postawko, S. E. (1997), The persistence of equatorial ground ice on Mars. Journal of Geophysical Research, 102(E8), 19357-19369.

Mellon, M. T., Feldman, W. C., \& Prettyman, T. H. (2004), The presence and stability of ground ice in the southern hemisphere of Mars. Icarus, 169, 324-340.

Mellon, M. T., Arvidson, R. E., Sizemore, H. G., Searls, M. L., Blaney, D. L., Cull, S., Hecht, M. H., Heet, T. L., Keller, H. U., Lemmon, M. T., Markiewicz, W. J., Ming, D. W., Morris, R. V., Pike, W. T., Zent, A. P. (2009), Ground ice at the Phoenix landing site: Stability state and origin. J. Geophys. Res. 114, E00E07. DOI:10.1029/2009JE003417.

Schorghofer, N., \& Edgett, K.S. (2006), Seasonal surface frost at low latitudes on Mars. Icarus, 180, 321-334. https://doi.org/10.1016/j.icarus.2005.08.022

Schorghofer, N., \& Forget, F. (2012), History and anatomy of subsurface ice on Mars. Icarus, 220(2), 1112-1120. https://doi.org/10.1016/jicarus.2012.07.003

Schulze-Mauch, D., Davila, A., Fairen, A.G., Rodriguez, A.P., Rask, J., Zavaleta, J. (2016), Sixth Mars Polar Science Conference, 6014.

Sinha, R.K., and Vijayan, S. (2017), Geomorphic Investigation of craters in Alba Mons, Mars: Implications for Late Amazonian glacial activity in the region, Planetary and Space Science, 144, 32-48. https://doi.org/10.1016/j.pss.2017.05.014.

Vincendon, M., Mustard, J., Forget, F., Kreslavsky, M., Spiga, A., Murchie, S., \& Bibring, J.-P. (2010), Near-tropical subsurface ice on Mars. Geophysical Research Letters, 37, L01202. https://doi.org/10.1029/2009GL041426

Viola, D., McEwen, A.S., Dundas, C.M., Byrne, S. (2015), Expanded secondary craters in the Arcadia Planitia region, Mars: Evidence for tens of Myr-old shallow subsurface ice. Icarus, 248, 190-204.

Viola, D. (2020), Age-dating of ice-rich mid-latitude mantle deposits on Mars. 51 ${ }^{\text {st }}$ Lunar and Planetary Science Conference, abstract\#2872. 
397 Viviano-Beck, C. E., et al. (2014), Revised CRISM spectral parameters and summary products 398 based on the currently detected mineral diversity on Mars, J. Geophys. Res. Planets, 119, 1403399 1431, DOI:10.1002/2014JE004627.

400 Viviano-Beck, C. E. et al. (2015), MRO CRISM Type Spectra Library, NASA Planetary Data $401 \quad$ System. https://crismtypespectra.rsl.wustl.edu 
Data and Methods:

In this study, we have used datasets from Mars Reconnaissance Orbiter (MRO), Mars Global Surveyor (MGS) and Mars Express (MEx). This includes photogeological and spectral datasets. More information regarding the date, time and season of observation about the datasets used is provided in Table S2 and Table S3.

Spectral datasets of CRISM were processed using the CAT tool extension added in ENVI. We applied photometric, atmospheric, destrip and despike corrections (inbuilt within the CAT tool) to the CRISM full resolution (FRT) and half resolution (HRL) datasets. After these corrections, we projected the CRISM image and spectra were taken up to 2.6 micro-meter wavelength. To remove the noise, the spectra was ratioed with the dust spectra taken in the same column. Thus, spectra given in Fig 2 are ratioed I/F spectra of the region of interest.

For age determination, we carefully marked the ejecta boundary of craters UC1 and UC2 (Fig S9) and did a robust counting of craters which superposed over the ejecta to determine the ages. We used the production function of Hartmann, 2005 and chronology function of Hartmann and Neukum, 2001. Poisson timing analysis (Michael, 2013) was used to determine the modelled age of craters UC1 and UC2 using cumulative crater size frequency distribution. To verify it, we determine the age of craters using differential distribution (Fig S12), and the ages are found similar to those determined using cumulative distribution.

To determine the age of smooth unit within UC1 (Fig S7) where no craters were observed we first determined the upper limit of a crater that should be observed, if present, over that unit. This limit is determined as $20 \mathrm{~m}$ based on the texture of the unit. Then using the area of the smooth unit which is determined as $7.8 \mathrm{~km}^{2}$, we calculated number of craters per $\mathrm{km}^{2}$. This value $\left(0.12 \mathrm{craters} / \mathrm{km}^{2}\right)$ is plotted in Fig $\mathrm{S} 11$ similar to Hartmann, 2005. Similar, methodology was followed to determine the age of smooth unit within UC2. Here, the area of the smooth unit is $10.93 \mathrm{~km}^{2}$, which gives $0.09 \mathrm{craters} / \mathrm{km}^{2}$. This again plotted (Fig S13) similar to Hartmann, 2005.

\author{
Figures S1 to S11: \\ $<$ Insert Figures S1 to S11> \\ Tables S1 to S3: \\ $<$ Insert tables S1>
}


443 Table S2. Details of CRISM images used in this study.

444

\begin{tabular}{|c|c|c|c|c|c|c|}
\hline Product ID & Date & Time & Date & Time & $\begin{array}{l}\text { Solar } \\
\text { Longitude }\end{array}$ & Seasons \\
\hline Unnamed crater 1 & & & & & & \\
\hline $\begin{array}{l}\text { FRT000247B6_07_IF169 } \\
\text { L }\end{array}$ & 2012-04-21 & 00:35:01 & 2012-04-21 & $00: 37: 33$ & $99.7^{\circ}$ & $\begin{array}{l}\text { Northern } \\
\text { Summer }\end{array}$ \\
\hline $\begin{array}{l}\text { FRT0002498F_07_IF167 } \\
\text { L }\end{array}$ & $2012-04-27$ & 04:19:04 & $2012-04-27$ & $04: 21: 20$ & $102.5^{\circ}$ & $\begin{array}{l}\text { Northern } \\
\text { Summer }\end{array}$ \\
\hline Unnamed crater 2 & & & & & & \\
\hline $\begin{array}{l}\text { HRL00018499_07_IF184 } \\
\text { L }\end{array}$ & $2010-04-26$ & $00: 47: 14$ & 2010-04-26 & $00: 49: 29$ & $82.6^{\circ}$ & $\begin{array}{l}\text { Northern } \\
\text { spring }\end{array}$ \\
\hline
\end{tabular}

445 Table S3. Details of HiRISE images used in this study.

\begin{tabular}{|l|l|l|l|l|}
\hline Product ID & Date & Time & $\begin{array}{l}\text { Solar } \\
\text { longitude }\end{array}$ & Seasons \\
\hline
\end{tabular}




\begin{tabular}{|c|c|c|c|c|}
\hline \multicolumn{5}{|l|}{ Unnamed crater 1} \\
\hline ESP_035517_2355 & $2014-02-23$ & $00: 27: 6$ & $93.5^{\circ}$ & $\begin{array}{l}\text { Northern } \\
\text { Summer }\end{array}$ \\
\hline ESP_035174_2355 & 2014-01-27 & 07:59:43 & $81.7^{\circ}$ & $\begin{array}{l}\text { Northern } \\
\text { Spring }\end{array}$ \\
\hline ESP_026880_2355 & 2012-04-21 & 00:06:10 & $99.7^{\circ}$ & $\begin{array}{l}\text { Northern } \\
\text { Summer }\end{array}$ \\
\hline ESP_026959_2355 & 2012-04-27 & 04:50:05 & $102.5^{\circ}$ & $\begin{array}{l}\text { Northern } \\
\text { Summer }\end{array}$ \\
\hline ESP_033974_2355 & $2013-10-26$ & $19: 45: 11$ & $40.6^{\circ}$ & $\begin{array}{l}\text { Northern } \\
\text { Spring }\end{array}$ \\
\hline ESP_033684_2355 & 2013-10-03 & $04: 25: 34$ & $30.4^{\circ}$ & $\begin{array}{l}\text { Northern } \\
\text { Spring }\end{array}$ \\
\hline ESP_062853_2355 & $2019-12-24$ & $15: 11: 00$ & $125.0^{\circ}$ & $\begin{array}{l}\text { Northern } \\
\text { Summer }\end{array}$ \\
\hline \multicolumn{5}{|l|}{ Unnamed crater 2} \\
\hline ESP_017563_2375 & $2010-4-26$ & $0: 18: 17$ & $82.5^{\circ}$ & $\begin{array}{l}\text { Northern } \\
\text { Spring }\end{array}$ \\
\hline ESP_018420_2375 & $2010-7-2$ & 19:0:46 & $112.3^{\circ}$ & $\begin{array}{l}\text { Northern } \\
\text { Summer }\end{array}$ \\
\hline PSP_008425_2375 & $2008-5-14$ & $23: 59: 23$ & $71.5^{\circ}$ & $\begin{array}{l}\text { Northern } \\
\text { Spring }\end{array}$ \\
\hline
\end{tabular}

